\title{
Utilization of fetal fibronectin testing and pregnancy outcomes among women with symptoms of preterm labor
}

This article was published in the following Dove Press journal:

ClinicoEconomics and Outcomes Research

3 October 2017

Number of times this article has been viewed

\author{
Sean C Blackwell' \\ Erin M Sullivan ${ }^{2}$ \\ Allison A Petrilla ${ }^{2}$ \\ Xian Shen ${ }^{2}$ \\ Kathleen A Troeger ${ }^{3}$ \\ James D Byrne ${ }^{4}$ \\ 'Department of Obstetrics, \\ Gynecology and Reproductive \\ Sciences, University of Texas Health \\ Sciences Center, Houston, TX, \\ USA; ${ }^{2}$ Avalere Health, LLC, Health \\ Economics and Outcomes Research, \\ Washington, DC, USA; ${ }^{3}$ Hologic, Inc. \\ Outcomes Research, Marlborough, \\ MA, USA; ${ }^{4}$ Department of Obstetrics \\ and Gynecology, Santa Clara Valley \\ Medical Center, San Jose, CA, USA
}

Correspondence: Erin M Sullivan Avalere Health, LLC, I350 Connecticut Avenue NW, Washington, DC 20036, USA

$\mathrm{Tel}+\mathrm{I} 6178170146$

Fax +l 2024674455

Email esullivan@avalere.com
Objectives: To identify pregnant health plan members triaged through the emergency department (ED), including labor and delivery (ELD) units, with symptoms of preterm labor (PTL), and evaluate the use of fetal fibronectin (fFN) testing; and to calculate the rate of hospitalization and timing of delivery in relation to the ED visit.

Methods: Retrospective cohort study using Medical Outcomes Research for Effectiveness and Economics Registry ${ }^{\circledR}$, a national multipayer claims database. A cohort of pregnant women evaluated in an ELD with a diagnosis of PTL from June 2012 through November 2015 was identified. The proportion of women with PTL who received fFN testing was calculated.

Results: A total of 23,062 patients met the criteria for inclusion in the study. The rate of fFN testing prior to delivery was $12.0 \%$. Of the 23,062 patients included in the analysis, $75.9 \%$ were discharged home. Of those who were discharged from the emergency room, one in five went on to deliver within 3 days and almost $96 \%$ of this group was not screened for the presence of fFN. Of the remaining $24.1 \%$ of patients admitted to the hospital, $91.3 \%$ delivered during their stay. In a sensitivity analysis, the percentage of women who delivered within 3 days of the ELD encounter was lower for women who received fFN testing only $(6.6 \%)$ versus those who had a history of transvaginal ultrasound (TVUS) only $(21.6 \%)$. Furthermore, the rate of delivery within 3 days was lowest among patients who had both fFN testing and TVUS (4.7\%).

Conclusion: The utilization of fFN testing is $12 \%$. The majority of pregnant patients triaged through the ELD with symptomatic PTL do not receive an fFN test. As part of PTL evaluation, fFN testing may identify women at increased risk for preterm delivery and help determine appropriate patient management.

Keywords: preterm labor, pregnancy, emergency department, fetal fibronectin testing

\section{Introduction}

In the USA, $\sim 1$ in 10 infants are delivered prematurely. ${ }^{1}$ Preterm delivery before the 37 th week of gestation is a leading cause of infant morbidity and mortality, and it is associated with high medical costs, with costs especially high in the first year following birth. ${ }^{2}$ The premature birth rate is high in the USA compared to other developed countries, ${ }^{3}$ and although the premature birth rate had experienced several years of decline, more recent data indicate that it may once again be on the rise. ${ }^{4}$

Preterm labor (PTL) is defined by the American College of Obstetricians and Gynecologists (ACOG) as regular contractions starting prior to 37 weeks of pregnancy that result in changes in the cervix. ${ }^{5}$ Diagnosis of PTL based on reported patient symptoms has shown to have relatively poor predictive value for risk of preterm delivery. ${ }^{6} \mathrm{Health}$ 
care professionals consider a number of clinical factors when making a diagnosis of PTL, including history of prior preterm delivery, transvaginal cervical length, presence of prenatal complications and other factors. ${ }^{7,8}$ Testing for presence or leakage of fetal fibronectin (fFN) during the 24th-34th weeks of pregnancy in symptomatic women may provide information that allows clinicians to rule out patients at a low risk for delivery within the following 14 days. ${ }^{9,10}$ Results from an fFN evaluation may allow clinicians to better identify patients at risk and guide patient management. A recent systematic review revealed that the standard clinical practice of diagnosing PTL by documenting uterine contractions and cervical change has poor positive predictive value. The authors further concluded that a newer approach of considering both $\mathrm{fFN}$ and cervical length screening results could lead to more accurate assessment of the risk for preterm delivery. ${ }^{11}$

Accurate assessment of the risk of preterm delivery among women with symptomatic PTL is critical to informing appropriate care management. Specifically, interventions such as targeted antenatal corticosteroids are beneficial for improving pregnancy outcomes for women who are at high risk for imminent preterm delivery, but may be unnecessary or potentially harmful for those who are at low risk for preterm delivery. The ACOG recommends a single course of corticosteroids for pregnant women between 24 and 34 weeks of gestation who are at risk of preterm delivery within 7 days ${ }^{12,13}$ however, concerns have been raised regarding the long-term consequences of repeated interventions on neurodevelopment and metabolism. ${ }^{14-16}$ In addition, ruling out patients who are at low risk for delivery within 7 days can help avoid unnecessary interventions and improve efficiency of care. Studies have demonstrated that approximately half of women who are initially hospitalized with symptoms of PTL do not deliver during that admission. ${ }^{17,18}$

The objective of this study was to evaluate patterns of health care utilization, including the use of fFN testing, and pregnancy outcomes among a USA cohort of pregnant women who present at, and are triaged through, an emergency department (ED) and/or labor and delivery (ELD) setting with a diagnosis of symptomatic PTL.

\section{Methods}

We performed a retrospective cohort study using the Inovalon Medical Outcomes Research for Effectiveness and Economics Registry (MORE² Registry). The MORE ${ }^{2}$ Registry is a proprietary database that contains claims data for $>137$ million unique and de-identified health plan members enrolled in commercial plans (employer-sponsored or Marketplace), managed Medicaid or Medicare Advantage plans. The registry represents $\sim 40 \%$ of the managed Medicaid and $25 \%$ of the Medicare Advantage population in the USA during a given year. Previous studies have used the MORE ${ }^{2}$ Registry to assess patterns of care, comparative effectiveness of treatments and quality of care across various therapeutic areas. ${ }^{19-22}$ Current procedural terminology $\left(\mathrm{CPT}^{\circledR}\right)$ and diagnosis-related group (DRG) codes were used to identify eligible women for the study. This study is an analysis of existing de-identified data. Approval from an institutional review board is not required.

\section{Inclusion/exclusion criteria}

Pregnant women who presented at the ELD with a diagnosis of PTL from June 1, 2012 to November 30, 2015 were included in the analysis. ICD-9-CM diagnosis and DRG codes (Table S1) were used to identify PTL patients. Women with no record of infant delivery during the 9-month period following the PTL diagnosis and women with $<20$ weeks of insurance coverage prior to delivery (Figure 1) were excluded from the analysis. Women with the following pregnancy complications in the 20 weeks prior to delivery were also excluded from the study: 1) spontaneous/premature rupture of membranes, 2) preeclampsia, 3) threatened abortion or 4) selected infections or pregnancy-related complications. ICD-9-CM diagnosis codes reported in the inpatient and outpatient medical claims files were used to identify patients with these conditions (Table S2).

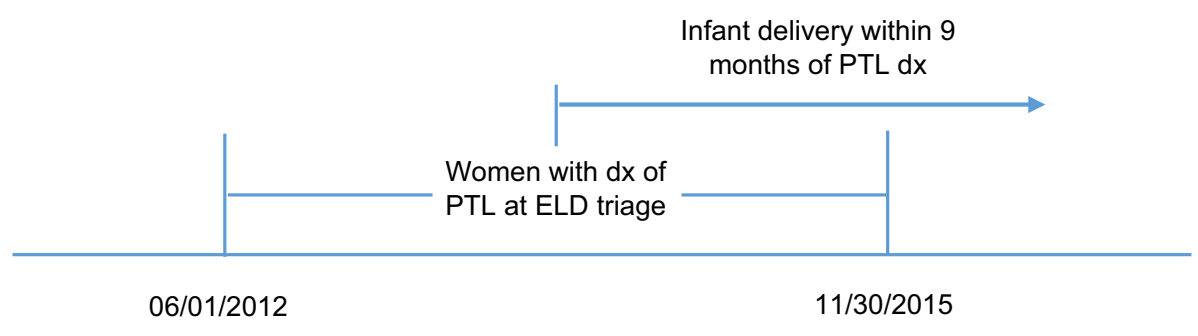

Figure I Schematic of study design.

Abbreviations: $\mathrm{dx}$, diagnosis; ELD, labor and delivery; PTL, preterm labor. 


\section{Study outcomes}

Study outcomes included 1) rates of hospital admission (e.g., to ELD unit) versus discharge (e.g., sent home) following the assessment of PTL; 2) timing of infant delivery following the ELD visit; and 3) length of stay (LOS) among patients admitted to the inpatient ward.

We measured patients' receipt of fFN testing (CPT code: 82731 ) during the 20 weeks prior to infant delivery. In addition, we evaluated patients' baseline characteristics, including demographics (age, geographic region and type of insurance coverage) and rates of comorbid conditions (hypertension, diabetes, gestational diabetes and cervical incompetence [Table S3]). We also examined health care resource utilization during the 20 weeks prior to delivery, including the frequency of outpatient physician office visits and the use of transvaginal ultrasound (TVUS) (CPT code: 76817).

Descriptive analyses were performed to describe the characteristics of the study cohort and key study outcomes.
Logistic regression analyses were used to assess predictors of fFN testing after adjusting for potential confounding baseline patient characteristics (e.g., age, comorbid conditions, insurance coverage and geographic region) and health care utilization (e.g., use of TVUS and number of physician visits during the 20 -week period prior to infant delivery). In addition, a sensitivity analysis was performed to assess pregnancy outcomes among the proportion of patients who received 1) fFN testing only, 2) TVUS only, 3) both tests and 4) neither test during the 20 -week predelivery period (including the initial ELD visit).

\section{Results}

A total of 23,062 patients met the study eligibility criteria and were included in the analysis (Figure 2). The mean age of the study cohort was 27.1 years (Table 1), and $9.2 \%$ were $\geq 36$ years. Approximately $20 \%$ of the patients lived in the Midwest region of the USA, $34.3 \%$ in the Northeast, $10.1 \%$

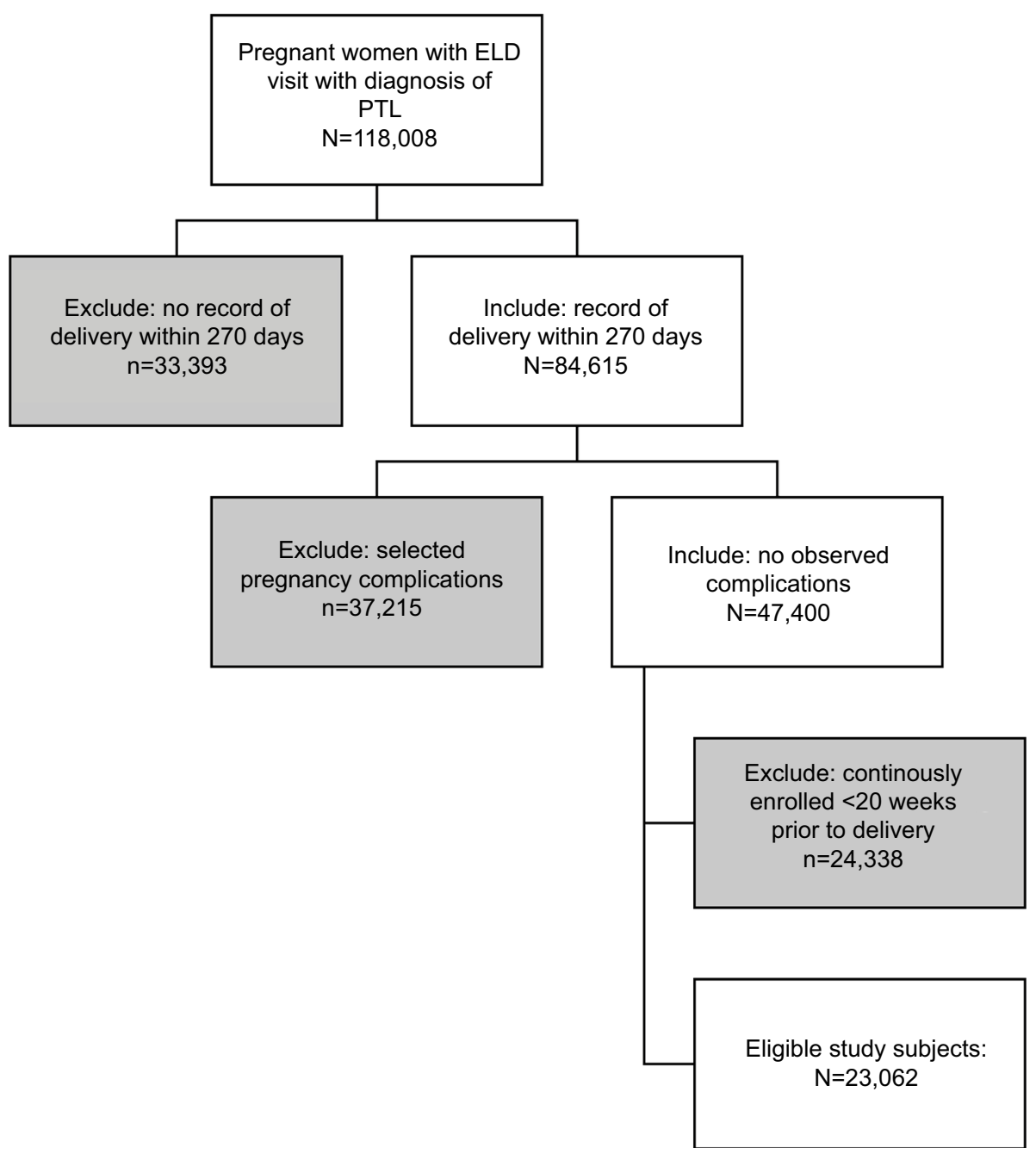

Figure 2 Study cohort identification. 
in the West and 36.0\% in the South. The majority (61.1\%) of patients were enrolled in a managed Medicaid program versus $19.2 \%$ with commercial coverage, and the remainder with other or multiple coverage types (as the type of insurance may have changed during the prenatal period). The percentage of

Table I Baseline characteristics of study cohort

\begin{tabular}{|c|c|}
\hline Measure & Value \\
\hline Overall & 23,062 \\
\hline \multicolumn{2}{|l|}{ Age group, years (column \%) } \\
\hline$\leq 20$ & $3,060(13.3)$ \\
\hline $21-25$ & $6,929(30.1)$ \\
\hline $26-30$ & $6,425(27.9)$ \\
\hline $31-35$ & $4,517(19.6)$ \\
\hline$\geq 36$ & $2,131(9.2)$ \\
\hline \multicolumn{2}{|l|}{ Age } \\
\hline Mean, SD & $27.1(5.9)$ \\
\hline \multicolumn{2}{|l|}{ Geographic region (column \%) } \\
\hline Midwest & $4,520(19.6)$ \\
\hline Northeast & $7,888(34.3)$ \\
\hline West & $2,327(10.1)$ \\
\hline South & $8,276(36.0)$ \\
\hline \multicolumn{2}{|l|}{ Insurance coverage (column \%) } \\
\hline Managed Medicaid & $14,094(6 \mid .1)$ \\
\hline Commercial & $4,423(19.2)$ \\
\hline Commercial and managed Medicaid coverage & $2,206(9.6)$ \\
\hline Other & $2,339(10.1)$ \\
\hline \multicolumn{2}{|l|}{ Comorbid conditions (\%) } \\
\hline Hypertension & I,889 (8.2) \\
\hline Comorbid diabetes & $\mathrm{I}, 035(4.5)$ \\
\hline Gestational diabetes & $2,583(11.2)$ \\
\hline Cervical incompetence & $76(0.3)$ \\
\hline \multicolumn{2}{|l|}{ Resource utilization } \\
\hline \multicolumn{2}{|l|}{ Number of physician visits (all cause; \%) } \\
\hline 0 & $2,777(12.0)$ \\
\hline $\mathrm{I}-5$ & $7,252(31.5)$ \\
\hline $6-10$ & $5,293(23.0)$ \\
\hline $11-15$ & $4,304(18.7)$ \\
\hline $16-20$ & $2,075(9.0)$ \\
\hline$\geq 21$ & $\mathrm{I}, 36 \mathrm{I}(5.9)$ \\
\hline Any transvaginal ultrasound prior to delivery (\%) & $4,953(21.5)$ \\
\hline
\end{tabular}

patients with comorbid hypertension and diabetes was $8.2 \%$ and $4.5 \%$, respectively. Approximately $11.2 \%$ of patients $(n=2,583)$ were diagnosed with gestational diabetes. Only $76(0.3 \%)$ patients had evidence of cervical incompetence captured based on the presence of diagnosis code $622.5 \mathrm{x}$. During the 20 -week period prior to infant delivery, $\sim 12 \%$ of the patients did not have any reported visits to a physician office. Approximately $21.5 \%$ of the patients received a TVUS during the 20 weeks prior to delivery.

Of the 23,062 patients in the study cohort, $\sim 12 \%$ received an $\mathrm{fFN}$ test during the 20 weeks prior to delivery. $84.5 \%$ of women who received an fFN test were tested on or before presenting to the ELD. The rate of fFN testing was comparable across insurance types: $12.8 \%$ for commercially insured, $11.6 \%$ for managed Medicaid insured, $13.7 \%$ for those experiencing both types of insurance (indicating patients changed insurance coverage during prenatal period) and $11.1 \%$ for those with other insurance types (Figure 3).

Approximately $24.1 \%$ of patients triaged through the ELD were admitted to the hospital, of which $91.3 \%$ delivered during that stay (mean LOS 4.0 days [ \pm 4.9$]$ ) (Figure 4). The remaining $75.9 \%$ of patients were discharged home, of which $20.1 \%$ delivered within the next 3 days. The proportion of women who had received fFN testing was higher for patients discharged home versus those admitted to a hospital $(14.2 \%$ vs. $5.0 \%, p<0.0001)$. Of those who were discharged from the emergency room, one in five went on to deliver within 3 days and almost $96 \%$ of this group was not screened for the presence of fFN.

After adjusting for potential confounding variables, patients residing in the Northeast (odds ratio $[\mathrm{OR}]=0.44$, 95\% CI: 0.39-0.49) were less likely to receive fFN testing than their counterparts living in the South, while patients living in the West had higher odds for receiving the test

Percentage of patients who had fFN testing

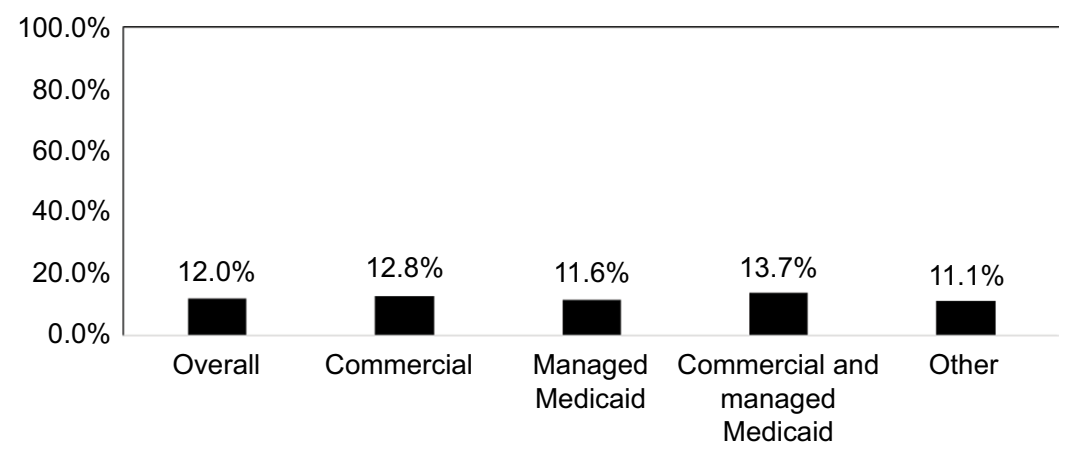

Figure 3 Prenatal fFN by type of insurance.

Abbreviation: fFN, fetal fibronectin. 


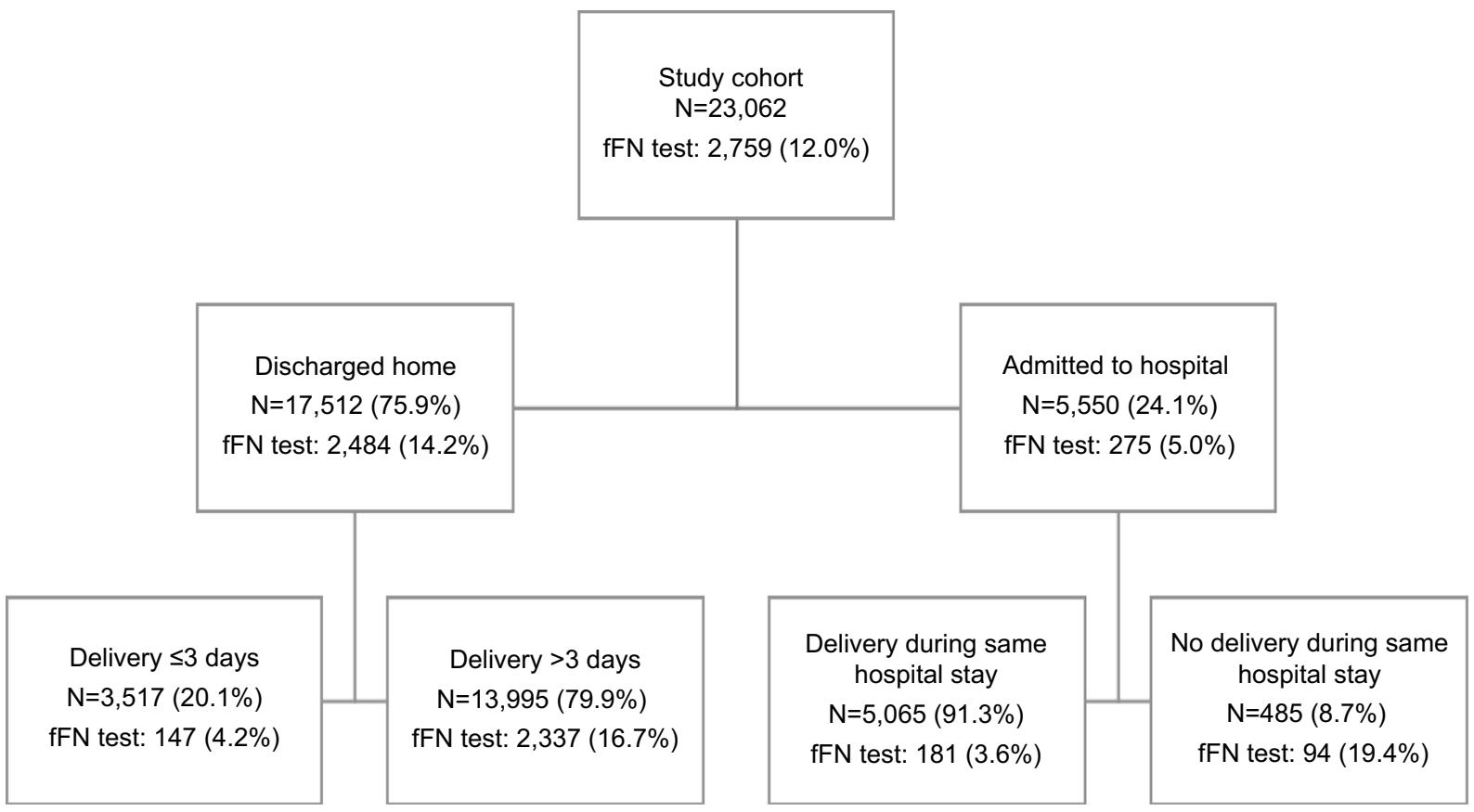

Figure 4 ELD triage status, timing of infant delivery and use of fFN testing. Abbreviations: ELD, labor and delivery; fFN, fetal fibronectin.

$(\mathrm{OR}=1.16$, 95\% CI: 1.01-1.32). In addition, patients who had more frequent all-cause physician visits (11-15 visits: $\mathrm{OR}=1.36,95 \% \mathrm{CI}: 1.20-1.55$; $16-20$ visits: $\mathrm{OR}=1.88,95 \%$ CI: $1.61-2.18$; $\geq 21$ visits: $\mathrm{OR}=2.93,95 \% \mathrm{CI}: 2.50-3.44)$ were more likely to receive fFN testing. Patients who received a TVUS during the 5 months prior to delivery were also more likely to receive fFN testing (OR=2.32, 95\% CI: 2.12-2.53). Patient age, type of insurance and presence of comorbid pregnancy complications were not shown to be predictors of fFN testing after adjustment for potential confounding characteristics (Table 2).

\section{Discussion}

This study is one of the first to assess the use of fFN screening and pregnancy outcomes among women diagnosed with PTL using medical claims data. In this national sample of managed care Medicaid and privately insured women, those who presented to the ELD with a diagnosis of PTL had relatively low rates of screening for risk of preterm delivery using fFN testing (12\%), regardless of the type of health insurance. Among patients who were discharged from the hospital, $14.2 \%$ had fFN testing compared to $5.0 \%$ of patients who were admitted to the hospital. Of women discharged home, one in five delivered prematurely within 3 days. Only $4.2 \%$ of these women had fFN evaluation, suggesting that there may
Table 2 Predictors of fetal fibronectin testing

\begin{tabular}{|c|c|c|}
\hline Measure & $\begin{array}{l}\text { Odds } \\
\text { ratio }\end{array}$ & $95 \% \mathrm{Cl}$ \\
\hline \multicolumn{3}{|l|}{ Overall } \\
\hline \multicolumn{3}{|l|}{ Age group (ref group: $\leq 20$ years) } \\
\hline $21-25$ & 0.95 & $0.83-1.09$ \\
\hline $26-30$ & 0.98 & $0.85-1.12$ \\
\hline $31-35$ & 0.89 & $0.77-1.04$ \\
\hline$\geq 36$ & 0.88 & $0.73-1.05$ \\
\hline \multicolumn{3}{|l|}{ Geographic region (ref group: South) } \\
\hline Midwest & 0.93 & $0.82-1.05$ \\
\hline Northeast & 0.44 & $0.39-0.49$ \\
\hline West & 1.16 & $1.01-1.32$ \\
\hline \multicolumn{3}{|l|}{ Insurance coverage (ref group: commercial) } \\
\hline Managed Medicaid & 0.94 & $0.83-1.07$ \\
\hline Managed Medicaid and commercial & 1.09 & $0.93-1.28$ \\
\hline Other/unknown & 1.15 & $0.95-1.38$ \\
\hline \multicolumn{3}{|l|}{ Baseline comorbidities } \\
\hline Cervical incompetence (ref group: No) & 1.00 & $0.57-1.76$ \\
\hline Hypertension (ref group: No) & 1.05 & $0.9|-| .2 \mid$ \\
\hline Comorbid diabetes (ref group: No) & 1.04 & $0.85-1.27$ \\
\hline Gestational diabetes (ref group: No) & 1.06 & $0.93-1.22$ \\
\hline \multicolumn{3}{|l|}{ Resource utilization } \\
\hline \multicolumn{3}{|l|}{ Number of physician visits (ref group: 6-10) } \\
\hline None & 1.10 & $0.95-1.28$ \\
\hline $1-5$ & 0.93 & $0.82-1.05$ \\
\hline $11-15$ & 1.36 & $1.20-1.55$ \\
\hline $16-20$ & 1.88 & $1.61-2.18$ \\
\hline$\geq 21$ & 2.93 & $2.50-3.44$ \\
\hline $\begin{array}{l}\text { Any transvaginal ultrasound prior to delivery (ref } \\
\text { group: No) }\end{array}$ & 2.32 & $2.12-2.53$ \\
\hline
\end{tabular}


be opportunities to improve the care management of these patients with the use of such screening tools as fFN testing. We also observed that $91.3 \%$ of the patients admitted to the hospital delivered during the hospital stay. This estimate is higher than the $50 \%$ delivery rate reported in the McPheeters study. ${ }^{17}$ A few explanations may be considered. Clinical practice might have evolved significantly since the McPheeters study. The 91.3\% delivery rate observed from this research indicates that significant advancement has occurred in the aspect of accurately identifying patients who are at imminent risk for delivery. In addition, the McPheeters study is a prospective cohort study of a population of 234 women with threatened PTL who received care between 1995 and 2001, whereas our study is a retrospective claims analysis that included over 20,000 patients receiving care between 2012 and 2015. The differences in evolving clinical care, study design and sample size may have also contributed to the inconsistent estimates for delivery rate between this analysis and the McPheeters study.

FFN testing may be used in conjunction with TVUS, or in lieu of TVUS, to assess the risk of preterm delivery in patients with symptoms of PTL. The percentage of women who delivered within 3 days of the ELD encounter was lower for women who received fFN testing only $(6.6 \%)$ versus those who had a history of TVUS only $(21.6 \%)$, suggesting that the use of fFN testing may have added valuable information to inform patient care. Furthermore, the rate of delivery within 3 days was lowest among patients who had both fFN testing and TVUS (4.7\%). The differences were statistically significant $(p<0.0001)$.

In a sensitivity analysis, we measured the use of both TVUS and fFN tests among the subset of patients who were discharged home from the ELD (Figure 5). Among those women discharged from ELD who delivered within 3 days, $3 \%$ received fFN testing only, $18 \%$ received TVUS only, $1 \%$ received both tests and $78 \%$ received neither test. The proportion of women who received $\mathrm{fFN}$ testing was higher among those who delivered after 3 days: $11 \%$ received $\mathrm{fFN}$ only, $16 \%$ received TVUS only, $6 \%$ received both $\mathrm{fFN}$ and TVUS, and $67 \%$ received neither test.

After controlling for observable baseline characteristics, women who incurred higher resource utilization prior to delivery (based on the number of all-cause physician visits and receipt of TVUS) were more likely to have received fFN testing. These patients may have presented other clinical risk factors for PTL, which were recorded in the medical claims data. Unlike disparities in access to prenatal services demonstrated in other studies, ${ }^{23,24}$ the type of insurance (i.e., Medicaid vs. commercial) was not associated with the receipt of fFN testing in this analysis. However, the low overall rates of fFN testing among these insured beneficiaries should be evaluated further. Significant differences in rates of fFN testing were found by geographic region, with lower rates of fFN testing in the northeast to the southern region of the USA and higher rates in the West. The observed geographic
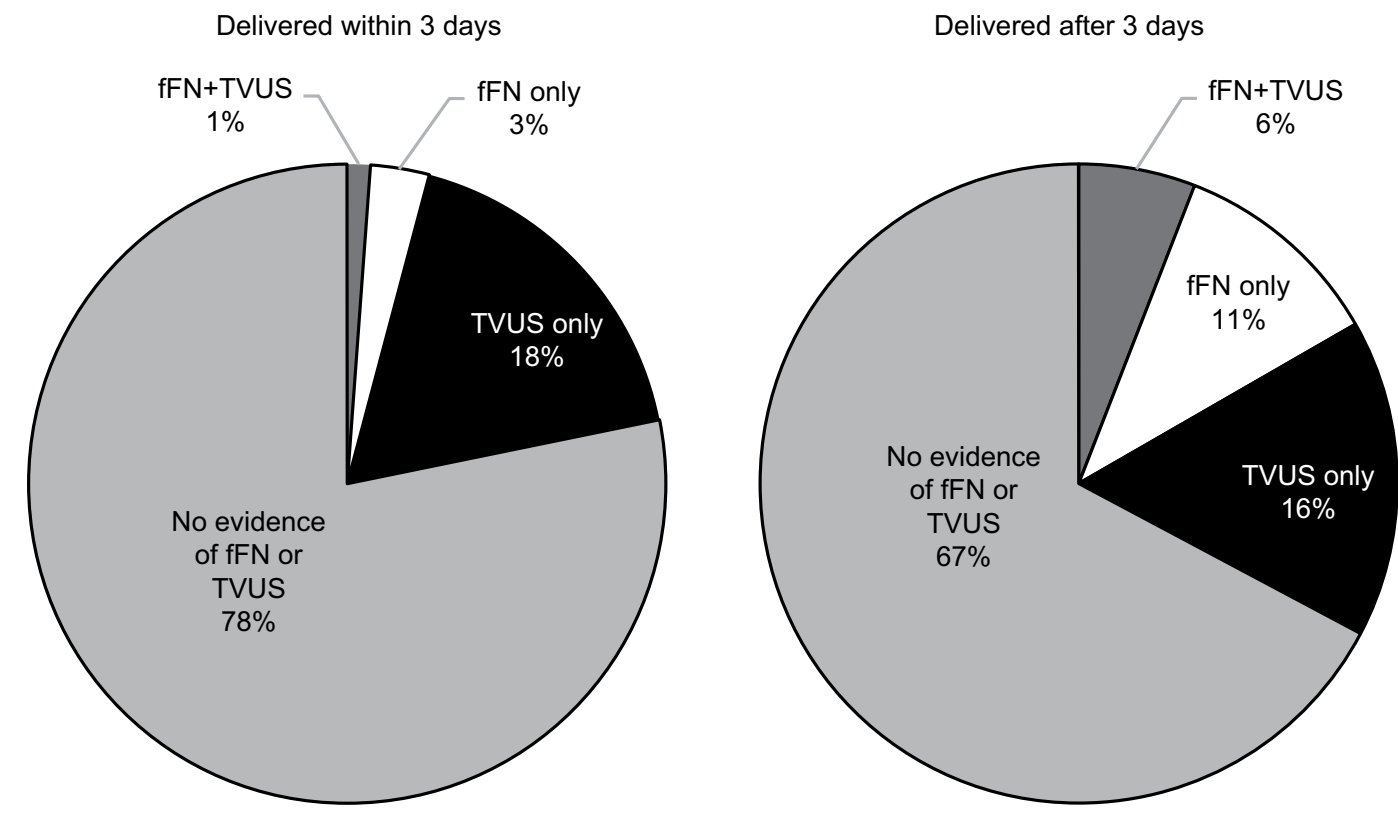

Figure 5 Sensitivity analysis: fFN and TVUS testing and time to delivery among patients discharged from ELD (N=17,5I2).

Note: Sensitivity analysis: fFN and TVUS testing among patients discharged from ELD who delivered within 3 days $(N=17,512)$.

Abbreviations: ELD, labor and delivery; fFN, fetal fibronectin; TVUS, transvaginal ultrasound. 
variation in $\mathrm{fFN}$ utilization highlights the potential differences in the patient population with symptomatic PTL and clinical practice patterns between the geographic regions. Given these findings, as well as studies showing the impact of gaps in access to appropriate care for high-risk women, ${ }^{25}$ additional research on the presence and implications of the geographic variation in the provision of prenatal care may be warranted. The cost-effectiveness of tests and techniques utilized in the evaluation of PTL was not an objective of this study, but continues to be a topic of discussion in the literature. This debate calls into focus the need for formal health economic evaluations of the total costs of care and maternal-newborn patient outcomes for large, real-world samples of women with PTL to identify practice patterns, techniques and geographic variations in care to better guide appropriate care management for pregnancies at risk for preterm delivery. As part of PTL evaluation, fFN testing may identify women at increased risk for preterm delivery and potentially decrease unnecessary interventions and hospital admissions for women and newborns identified at lower risk.

This study had several limitations. First, this study was limited by the ability to evaluate fFN clinical test results. Medical claims data are captured for the purpose of provider and supplier reimbursement and not for research purposes, and, as such, contain minimal clinical information. This could lead to a potential over- or underestimation of clinical events of interest. The absence of detailed clinical information further limits the evaluation of factors related to severity and symptoms of PTL such as cervical length, number of contractions per hour or results of fFN testing. Information regarding perinatal and obstetric outcomes is also limited. The study cohort was identified based on diagnoses codes recorded in medical claims. Coding errors and insufficient documentation of diagnoses codes may occur and could lead to misclassifying ineligible patients as eligible or vice versa. However, both PTL and the exclusion conditions (i.e., spontaneous/premature rupture of membranes, preeclampsia) are significant health events for which coding errors are conceivably rare. Researchers may consider conducting prospective cohort studies or analyzing electronic medical records to collect data on $\mathrm{fFN}$ results, which would strengthen the ability to gauge the current clinical practice for managing patients with symptomatic PTL under the guidance of fFN results. Despite these limitations, a strength of this study is that the results reflect actual patterns of care and pregnancy outcomes among PTL patients in a real-world setting. We found that utilization of fFN testing was lower among women who delivered within 3 days (or during hospital stay) than those who delivered later. We speculate that this observed correlation is attributable to the fact that clinicians are less likely to order fFN testing when patients' symptoms are clearly indicative of imminent preterm delivery (e.g., cervix $4 \mathrm{~cm}$ dilated or more). Second, the objective of the study was to assess the use of fFN testing among women in emergent situations, and we did not evaluate the incidence of PTL in the outpatient (physician office) setting prior to the ELD visit or utilization of antenatal steroids, which is currently recommended for women between 24 and 34 weeks of gestation who are at risk of preterm delivery. ${ }^{26}$ In addition, visibility into fFN testing was limited to the outpatient and ELD settings; we were unable to assess the use of fFN testing during an inpatient stay. As such, the rate of fFN testing among the inpatient cohort may be underestimated. Third, we examined the rates of TVUS to gauge the use of other methods of assessing the risk of preterm delivery among women diagnosed with PTL. Although we excluded the CPT codes associated with routine anatomy evaluations, the rates we observed in our analysis may also include anatomic ultrasounds scheduled as part of routine prenatal care, or miscoded, and not necessarily used to screen for PTL risk. Finally, the study cohort was restricted to insured women with symptomatic PTL who presented in the ELD. Hence, the study findings may not be generalizable to women without insurance or other settings of care. A strength of this evaluation, however, is that the majority of women in this evaluation had Medicaid insurance. Given that studies have shown that there is a disproportionately higher proportion of Medicaid women who have preterm births compared to women with commercial insurance, ${ }^{23}$ additional research evaluating screening for preterm delivery, management and pregnancy outcomes among Medicaid patients diagnosed with PTL should be considered. Finally, the analysis is focused on the use of fFN testing. Patients who did not receive an fFN testing might have been assessed for risk of preterm delivery using other methods or diagnostic tests.

Despite these limitations, the findings from this study suggest that fFN testing may be a useful component of screening to identify patients at lower risk for imminent preterm birth and inform care management. Additional research is needed to determine how to use quantitative fFN testing tools currently under development as part of screening for risk of PTL allowing physicians the opportunity to better understand patient risk factors and tailor interventions to optimize preand perinatal care for the woman and her neonate.

\section{Acknowledgment}

The abstract of this manuscript was presented as a poster presentation at the Internal Society for Pharmacoeconomics and Outcomes Research 22nd Annual International Meeting on May 23, 2017. 


\section{Disclosure}

EMS, AAP and XS are employees of Avalere Health, LLC which received funding from Hologic, Inc. to support the execution of this study and development of the paper. KAT is an employee of Hologic, Inc. SCB and JDB serve as medical experts but received no support for their participation in this paper. The authors report no other conflicts of interest in this work.

\section{References}

1. Hamilton BE, Martin JA, Osterman MJK, et al. Births: Final data for 2014. National Vital Statistics Reports; vol 64 no 12. Hyattsville, MD: National Center for Health Statistics. 2015.

2. Jacob J, Lehne M, Mischker A, Klinger N, Zickermann C, Walker J. Cost effects of preterm birth: a comparison of health care costs associated with early preterm, late preterm, and full-term birth in the first 3 years after birth. Eur J Health Econ. Epub 2016 Dec 1.

3. OECD (2017), Infant mortality rates (indicator). doi: 10.1787/83dea506en (Accessed on 24 March 2017).

4. Preterm Birth. Centers for Disease Control and Prevention. Accessible at: https:/www.cdc.gov/reproductivehealth/maternalinfanthealth/ pretermbirth.htm. Accessed on 28 August 2017.

5. American College of Obstetricians and Gynecologists' Committee on Practice Bulletins-Obstetrics. Practice bulletin no. 171: management of preterm labor. Obstet Gynecol. 2016;128(4):e155-e164.

6. Lucovnik M, Chambliss LR, Garfield RE. Costs of unnecessary admissions and treatments for "threatened preterm labor". Am J Obstet Gynecol. 2013;209(3):217.e1-e3.

7. American College of Obstetricians and Gynecologists; Committee on Practice Bulletins-Obstetrics. ACOG practice bulletin no. 127: management of preterm labor. Obstet Gynecol. 2012;119(6):1308-1317.

8. Committee on Practice Bulletins-Obstetrics, The American College of Obstetricians and Gynecologists. Practice bulletin no. 130: prediction and prevention of preterm birth. Obstet Gynecol. 2012;120(4):964-973.

9. Peaceman AM, Andrews WW, Thorp JM, et al. Fetal fibronectin as a predictor of preterm birth in patients with symptoms: a multicenter trial. Am J Obstet Gynecol. 1997;177(1):13-18.

10. Rapid fFN Instructions for Use. AW-04196-002 Rev. 002. Hologic Inc, Marlborough MA 01752. Available from: http://www.ffntest.com/pdfs/ rapid_ffn_speccollectkit_ifu.pdf. Accessed on 28 August 2017.

11. DeFranco EA, Lewis DF, Odibo AO. Improving the screening accuracy for preterm labor: is the combination of fetal fibronectin and cervical length in symptomatic patients a useful predictor of preterm birth? A systematic review. Am J Obstet Gynecol. 2013;208(3):233.e1-e6.
12. ACOG Committee on Obstetric Practice. ACOG Committee Opinion No. 475: antenatal corticosteroid therapy for fetal maturation. Obstet Gynecol. 2011;117(2 Pt 1):422-424.

13. Committee on Obstetric Practice. Committee Opinion No. 713: antenatal corticosteroid therapy for fetal maturation. Obstet Gynecol. 2017;130(2):e102-e109.

14. Shields A, Thomson M, Winter V, Coalson J, Rees S. Repeated courses of antenatal corticosteroids have adverse effects on aspects of brain development in naturally delivered baboon infants. Pediatr Res. 2012;71(6): 661-667.

15. McKinlay CJD, Cutfield WS, Battin MR, Dalziel SR, Crowther CA, Harding JE; ACTORDS Follow-up Group. Mid-childhood bone mass after exposure to repeat doses of antenatal glucocorticoids: a randomized trial. Pediatrics. 2017;139(5):e20164250.

16. Peltoniemi OM, Kari MA, Hallman M. Repeated antenatal corticosteroid treatment: a systematic review and meta-analysis. Acta Obstet Gynecol Scand. 2011;90(7):719-727.

17. McPheeters ML, Miller WC, Hartmann KE, et al. The epidemiology of threatened preterm labor: a prospective cohort study. Am J Obstet Gynecol. 2005;192(4):1325-1329; discussion 1329-1330.

18. Rose CH, McWeeney DT, Brost BC, Davies NP, Watson WJ. Costeffective standardization of preterm labor evaluation. Am J Obstet Gynecol. 2010;203(3):250.e1-e5.

19. Mehta S, Pulungan Z, Jones BT, Teigland C. Comparative safety of atypical antipsychotics and the risk of pneumonia in the elderly. Pharmacoepidemiol Drug Saf. 2015;24(12):1271-1280.

20. Sturmer T, Marquis MA, Zhou H, et al. Cancer incidence among those initiating insulin therapy with glargine versus human NPH insulin. Diabetes Care. 2013;36(11):3517-3525.

21. Pracilio VP, Silberstein S, Couto J, et al. Measuring migraine-related quality of care across 10 health plans. Am J Manag Care. 2012;18(8):e291-e299.

22. Meckley LM, Miyasato G, Kokkotos F, Bumbaugh J, Bailey RA. An observational study of glycemic control in canagliflozin treated patients. Curr Med Res Opin. 2015;31(8):1479-1486.

23. Markus AR, Krohe S, Garro N, Gerstein M, Pellegrine C. Examining the association between medicaid coverage and preterm births using 20102013 National Vital Statistics Birth Data. J Child Poverty. 2017, 23(1): 79-94.

24. Zhang S, Cardavelli K, Shim R, Ye J, Booker KL, Rust G. Racial disparities in economic and clinical outcomes of pregnancy among medicaid recipients. Matern Child Health J. 2013;17(8):1518-1525.

25. Brantley MD, Davis, NL, Goodman DA, Callaghan WM, Barfield WD. Perinatal regionalization: a geospatial view of perinatal critical care, United States, 2010-2013. Am JObstet Gynecol. 2017;216(2):185.e1-e10.

26. Joint Commission. Specifications Manual for Joint Commission National Quality Measures (v2013A1). Discharges 01-01-13 (1Q13) through 06-30-13 (2Q13). Available from: https://manual.jointcommission.org/releases/TJC2013A/MIF0168.html. Accessed April 6, 2017. 


\section{Supplementary materials}

Table SI Diagnosis and DRG codes for preterm labor

\begin{tabular}{ll}
\hline Code & Code description \\
\hline ICD-9-CM diagnosis & Threatened PTL \\
644 & Early or threatened labor \\
644.0 & Threatened premature labor \\
644.00 & Threatened premature labor, unspecified as to episode of care or not applicable (N/A) \\
644.0 I & Threatened premature labor delivered, with or without mention of antepartum condition \\
644.03 & Threatened premature labor, antepartum condition or complication \\
644.1 & Other threatened labor \\
644.10 & Other threatened labor, unspecified as to episode of care or N/A \\
644.13 & Other threatened labor, antepartum condition or complication \\
MS-DRG* & \\
780 & False labor \\
APR-DRG* & \\
$565-I$ to 565-4 & False labor \\
ICD-9-CM diagnosis & Actual PTL \\
644.2 & Early onset of delivery \\
644.20 & Early onset of delivery, unspecified as to episode of care or N/A \\
644.21 & Early onset of delivery, delivered, with or w/o mention of antepartum condition \\
\hline
\end{tabular}

Abbreviations: DRG, diagnosis-related group; PTL, preterm labor; ICD-9-CM; International Classification of Diseases, Ninth Revision, Clinical Modification; APR-DRG, All Patient Refined- Diagnosis Related Group; MS-DRG, Medicare Severity- Diagnosis Related Group.

Table S2 Diagnosis codes for exclusion criteria

\begin{tabular}{|c|c|}
\hline $\begin{array}{l}\text { ICD-9-CM } \\
\text { diagnosis }\end{array}$ & Code description \\
\hline 642.4 & Mild or unspecified preeclampsia \\
\hline 642.5 & Severe preeclampsia \\
\hline 642.6 & Eclampsia complicating pregnancy childbirth or the puerperium \\
\hline 642.7 & Preeclampsia or eclampsia superimposed on preexisting hypertension \\
\hline 658.1 & Premature rupture of membranes \\
\hline 640.0 & Threatened abortion \\
\hline 640.00 & Threatened abortion, unspecified as to episode of care or not applicable \\
\hline 640.01 & Threatened abortion, delivered, with or without mention of antepartum condition \\
\hline 640.03 & Threatened abortion, antepartum condition or complication \\
\hline \multicolumn{2}{|l|}{ MS-DRG } \\
\hline 778 & Threatened abortion \\
\hline \multicolumn{2}{|l|}{ APR-DRG } \\
\hline $563-1$ to $563-4$ & Threatened abortion \\
\hline \multicolumn{2}{|l|}{ Infections } \\
\hline 647.30 & $\begin{array}{l}\text { Tuberculosis of mother, complicating pregnancy, childbirth or the puerperium, unspecified as to episode of care or not } \\
\text { applicable }\end{array}$ \\
\hline 647.31 & $\begin{array}{l}\text { Tuberculosis of mother, complicating pregnancy, childbirth or the puerperium, delivered, with or without mention of } \\
\text { antepartum condition }\end{array}$ \\
\hline 647.32 & $\begin{array}{l}\text { Tuberculosis of mother, complicating pregnancy, childbirth or the puerperium, delivered, with mention of postpartum } \\
\text { complication }\end{array}$ \\
\hline 647.33 & Tuberculosis of mother, complicating pregnancy, childbirth or the puerperium, antepartum condition or complication \\
\hline 647.34 & Tuberculosis of mother, complicating pregnancy, childbirth or the puerperium, postpartum condition or complication \\
\hline 647.40 & Malaria in the mother, unspecified as to episode of care or not applicable \\
\hline 647.41 & Malaria in the mother, delivered, with or without mention of antepartum condition \\
\hline 647.43 & Malaria in the mother, antepartum condition or complication \\
\hline 647.50 & Rubella in the mother, unspecified as to episode of care or not applicable \\
\hline 647.51 & Rubella in the mother, delivered, with or without mention of antepartum condition \\
\hline 647.53 & Rubella in the mother, antepartum condition or complication \\
\hline 647.60 & Other viral diseases in the mother, unspecified as to episode of care or not applicable \\
\hline 647.61 & Other viral diseases in the mother, delivered, with or without mention of antepartum condition \\
\hline
\end{tabular}


Table S2 (Continued)

\begin{tabular}{|c|c|}
\hline $\begin{array}{l}\text { ICD-9-CM } \\
\text { diagnosis }\end{array}$ & Code description \\
\hline 647.63 & Other viral diseases in the mother, antepartum condition or complication \\
\hline 647.80 & Other specified infectious and parasitic diseases of mother, unspecified as to episode of care or not applicable \\
\hline 647.81 & Other specified infectious and parasitic diseases of mother, delivered, with or without mention of antepartum condition \\
\hline 647.83 & Other specified infectious and parasitic diseases of mother, antepartum condition or complication \\
\hline 647.90 & Unspecified infection or infestation of mother, unspecified as to episode of care or not applicable \\
\hline 647.91 & Unspecified infection or infestation of mother, delivered, with or without mention of antepartum condition \\
\hline 647.93 & Unspecified infection or infestation of mother, antepartum condition or complication \\
\hline 655.30 & $\begin{array}{l}\text { Suspected damage to fetus from viral disease in the mother, affecting management of mother, unspecified as to episode of } \\
\text { care or not applicable }\end{array}$ \\
\hline 655.31 & $\begin{array}{l}\text { Suspected damage to fetus from viral disease in the mother, affecting management of mother, delivered, with or without } \\
\text { mention of antepartum condition }\end{array}$ \\
\hline 655.33 & $\begin{array}{l}\text { Suspected damage to fetus from viral disease in the mother, affecting management of mother, antepartum condition or } \\
\text { complication }\end{array}$ \\
\hline 655.40 & $\begin{array}{l}\text { Suspected damage to fetus from other disease in the mother, affecting management of mother, unspecified as to episode of } \\
\text { care or not applicable }\end{array}$ \\
\hline \multicolumn{2}{|c|}{ Other complications } \\
\hline 655.41 & $\begin{array}{l}\text { Suspected damage to fetus from other disease in the mother, affecting management of mother, delivered, with or without } \\
\text { mention of antepartum condition }\end{array}$ \\
\hline 655.43 & $\begin{array}{l}\text { Suspected damage to fetus from other disease in the mother, affecting management of mother, antepartum condition or } \\
\text { complication }\end{array}$ \\
\hline 655.80 & $\begin{array}{l}\text { Other known or suspected fetal abnormality, not elsewhere classified, affecting management of mother, unspecified as to } \\
\text { episode of care or not applicable }\end{array}$ \\
\hline 655.81 & $\begin{array}{l}\text { Other known or suspected fetal abnormality, not elsewhere classified, affecting management of mother, delivered, with or } \\
\text { without mention of antepartum condition }\end{array}$ \\
\hline 655.83 & $\begin{array}{l}\text { Other known or suspected fetal abnormality, not elsewhere classified, affecting management of mother, antepartum condition } \\
\text { or complication }\end{array}$ \\
\hline 646.80 & Other specified complications of pregnancy, unspecified as to episode of care or not applicable \\
\hline 646.81 & Other specified complications of pregnancy, delivered, with or without mention of antepartum condition \\
\hline 646.83 & Other specified complications of pregnancy, antepartum condition or complication \\
\hline 646.90 & Unspecified complication of pregnancy, unspecified as to episode of care or not applicable \\
\hline 646.91 & Unspecified complication of pregnancy, delivered, with or without mention of antepartum condition \\
\hline 646.93 & Unspecified complication of pregnancy, antepartum condition or complication \\
\hline 752.35 & Uterine septum \\
\hline $740-759$ & Congenital anomalies \\
\hline 764.9 & Intrauterine growth retardation \\
\hline
\end{tabular}

Abbreviations: DRG, diagnosis-related group; PTL, preterm labor.

Table S3 ICD-9 Diagnosis codes for comorbid conditions

\begin{tabular}{lll}
\hline Condition & Code type & Code set \\
\hline Cervical incompetence & ICD 9 CM & $622.5 x$ \\
Hypertension & ICD 9 CM & $401 . x x, 405 . x x, 642.0 x, 642.2 x, 642.3 x$ \\
Gestational diabetes & ICD 9 CM & $648.80,648.81,648.82,648.83,648.84$ \\
Comorbid diabetes & ICD 9 CM & $250 . x x, 648.0 x$ \\
\hline
\end{tabular}

ClinicoEconomics and Outcomes Research

\section{Publish your work in this journal}

ClinicoEconomics and Outcomes Research is an international, peerreviewed open-access journal focusing on health technology assessment, pharmacoeconomics and outcomes research in the areas of diagnosis, medical devices, and clinical, surgical and pharmacological intervention. The economic impact of health policy and health systems

\section{Dovepress}

organization also constitute important areas of coverage. The manuscript management system is completely online and includes a very quick and fair peer-review system, which is all easy to use. Visit http://www.dovepress.com/testimonials.php to read real quotes from published authors. 